\title{
Attitudes and knowledge of obesity risks among Male high school students in Al-Madinah, Saudi Arabia
}

\author{
Awad Mohammed Al-Qahtani ${ }^{1,2^{*}}$, Hamza Sundogji ${ }^{2}$ \\ ${ }^{1}$ Department of Family \& Community Medicine, College of Medicine, Najran University, Najran, Saudi Arabia. \\ ${ }^{2}$ Ministry of health, Postgraduate studies of family medicine in Al-Madinah Al-Munawarah, Saudi Arabia.
}

\section{ARTICLE INFO \\ Article history: \\ Received on: 25/08/2016 \\ Revised on: 04/09/2016 \\ Accepted on: 30/09/2016 \\ Available online: 29/10/2016}

Key words:

Adolescent, Body Mass

Index, Obesity risks,

Attitudes, Overweight.

\begin{abstract}
The study aimed to evaluate the knowledge about obesity risks and attitude towards obese persons along with prevalence of obesity among high school students in Al-Madinah. This cross-sectional descriptive study included 314 male students enrolled in the secondary schools in Al-Madinah.Multi-stage random sampling technique was applied. Two reliable and valid questionnaires were utilized for data collection; The Obesity Risk knowledge scale (ORK) and Attitude toward Obese Persons (ATOP). Students' age ranged between 16 and 19 years with a mean of 17.08 years. The prevalence of overweight and obesity were $11.8 \%$ and $16.2 \%$ respectively. Overall, the knowledge score ranged between 0 and 7. Among 314 students, 241 had insufficient knowledge regarding obesity related issues with just 73 having sufficient knowledge. Students with positive attitude towards obese person were $53.2 \%$ whereas $46.8 \%$ had negative attitude. There was no association found between student's age and body mass index (BMI) with their knowledge regarding obesity risks \& attitude towards obese person. The study revealed Knowledge of the students regarding obesity risk factors was insufficient whereas their attitude towards obese persons is considered satisfactory along with high prevalence of overweight and obesity among the male adolescent population in Al-Madinah, KSA.
\end{abstract}

\section{INTRODUCTION}

Most of the world's population live in countries where overweight and obesity kills more people than underweight.Overweight and obesity are defined as abnormal or excessive fat accumulation that may impair health (WHOObesity and overweight, 2015). Non-communicable diseases (NCDs) kill 38 million people each year. Tobacco use, physical inactivity, the harmful use of alcohol and unhealthy diets all increase the risk of dying from an NCD (WHO-Noncommunicable diseases, 2015). Childhood obesity has more than doubled in children and quadrupled in adolescents in the

\footnotetext{
* Corresponding Author

Dr. Awad Mohammed Al-Qahtani, Department of Family \& Community Medicine, Faculty of Medicine, Najran University, Najran. Postgraduate studies of family medicine in Al-Madinah Al-Munawarah, Saudi Arabia. Tel: 00966530540450; Fax:0175417111,

Email:awadresearch17 @gmail.com
}

past 30 years. In 2012, more than one third of children and adolescents were overweight or obese (Ogden et al., 2014; National Center for Health Statistics, 2011). Obesity is defined as having excess body fat (Krebs et al., 2007), whereas over weight defined as increased body weight in relation to height when compared to standard of acceptable or desirable weight (Childhood overweight and obesity-Atlanta, 2012). Obesity is considered most important public health issue in male adolescents and it is growing concern in high school students. Several studies have been done on this subject either nationally or internationally. The prevalence of obesity estimated in USA, Kuwait and Germany is $24.6 \%, 24 \%$ and 19\% respectively (Bonauto et al., 2014; Karageorgi et al., 2013; Hoffmann et al., 2013). One study conducted in three major cities of Saudi Arabia: Al-Khobar, Jeddah, and Riyadh during 2009-2010 among Saudi adolescents has shown the prevalence of overweight $(19.5 \%)$, obesity $(24.1 \%)$, and abdominal obesity $(35.9 \%)$, among male students of secondary school (Al-Hazzaa et al., 2014). 
In Europe, a study was conducted to determine and compare attitudes, skills, and practices in childhood obesity management in 4 European countries namely France, Italy, Poland, and Ukraine. The study underlined insufficient implementation of national guidelines for management of obesity regardless of the country and its health system (Artur et al., 2013).

Both regional and national studies showed a trend of rising obesity over time. The latest national data revealed that the rates of overweight and obesity among school-age children have reached $23 \%$ and $9.3 \%$, respectively (Ali et al., 2013).

In order to prevent this increasing obesity prevalence, it is important that individuals are educated on obesity risk factors. Providing continuous professional education in obesity has been considered as the key factor by primary health care providers (Mazur et al., 2013). The main purpose of this study was to evaluate knowledge about obesity \& its risk factors and attitudes of male students toward the obese person. The study also included comparison between student's age and BMI with their knowledge and attitude towards obese person.

\section{MATERIAL AND METHODS}

\section{Study Design}

The study was conducted in Al-Madinah, second holiest city in Islam in 2014. This cross-sectional descriptive study included 314 male students enrolled in the secondary schools. Inclusion Criteria: All high school male students in the selected schools were eligible for study inclusion. Exclusion Criteria: No exclusion criteria.

\section{Sampling Technique} follows:

Multi-stage random sampling technique was adopted as

Stage 1: Stratifying Al-Madinah city into four geographical areas (east, west, north and south) Stage 2: List all male schools in the different areas north, south, East and West.

Stage 3: Selection of one school (using simple random method) from each of the four geographical areas was done.

Stage 4: In each school, there are three educational levels. The researcher selected one class from every level by using simple random method.

Stage 5: By using clustering method, all the students in the selected class were included in the study.

\section{Obesity Risk knowledge \& Attitude Test Construction}

Two reliable and valid questionnaires were used for data collection. First one is The Obesity Risk Knowledge scale (ORK). This questionnaire was self-administered and includes 9 items designed by Swift, Glaze brook and Macdonald (2006). The score ranged from 0-9 (Swift et al., 2006).

The second questionnaire was Attitude toward Obese Persons (ATOP). This questionnaire was self-administered and includes 15 items developed by Allison, Basile and Yuker (Allison et al., 1991). The scale is based on a six-point (ranging from $-3=$ strongly disagree to $+3=$ strongly agree), participants have to indicate the extent to which they agree or disagree with twenty statements regarding obese people. After finishing questionnaire Body mass index (BMI) was calculated for each student.

\section{Obesity Risk knowledge \& Attitude Test Validity \& Reliability}

As described by Kline, the ORK-10 scale having a level of internal consistency which exceeds the accepted minimum of a Cronbach's alpha $>0.7$ compared to the total scale. This scale measures extensive area of knowledge with relatively few items; which could be the cause for reduction in internal consistency. Considering the above fact significant results may be obtained (Kline, 2000).

\section{Pilot Study}

A pilot study was conducted on a purposive sample of 10 students which was not included in the main study. The main goals were to assess the accessibility, time required to fill the questionnaire, questions understanding and the response rate. As a feedback, the questionnaire was clear and an average of 10 minutes was required to complete it.

\section{Data analysis}

Data collection was done using excel and SPSS version 20.0. Descriptive statistics was done using frequency and percentage, whereas analytic statistics was done using chi-square test $\left(\mathrm{x}^{2}\right)$.

For Knowledge questions ( $n=9)$, a score of " 1 " was assigned to a correct response while a score of " 0 " was assigned to wrong or do not know response. Students scored at or above 50\% were considered as having "sufficient knowledge". For attitude questions $(n=15)$ a score ranged between -3 (strongly disagree) to +3 (strongly agree) was assigned to each statement. Students scored above the midpoint were considered as having "positive attitude" like moderately agree and above and those who scored below the midpoint were considered having negative attitude (moderately disagree and above).

\section{Ethical Considerations}

Ethical clearance was obtained from vice chair of medical research center, college of medicine, Najran University, KSA. The author took the approval from the male school authorities who gave the permission letter to all high schools directors to facilitate the work for the investigator. Written Consent was obtained from every individual.

\section{RESULTS}

\section{Body mass index}

The study included 314 students. Their age ranged between 16 and 19 years with a mean of 17.08 years. The prevalence of overweight and obesity were $11.8 \%$ and $16.2 \%$ 
respectively whereas underweight was reported among $15 \%$ of the participants. From Table 1, it is demonstrated that there was no significant association between body mass index (BMI) and student's age.

\section{Obesity knowledge}

Table 2 depicts the obesity knowledge among male high school students. Overall, the knowledge score ranged between 0 and 7 with a mean of $3.5 \pm 1.3$. Out of 314 , only $73(23.2 \%)$ students had sufficient knowledge regarding obesity risks whereas 241(76.8\%) had insufficient knowledge.
Out of 314 students $53.2 \%$ (167) of the students had positive attitude towards obese person whereas the remaining $46.8 \%$ (147) had negative attitude towards it (Table 3). There was no significant association between the student's age and BMI with their knowledge regarding obesity related risk factors. Also there was no significant correlation between the age of the students and BMI with their attitude towards obese person, as shown in Table 4.

From table 5, it was clear that there was no association between obesity knowledge among male high school students and their attitude towards obese persons.

Table 1: Age \& BMI of male high school students.

\begin{tabular}{|c|c|c|c|c|}
\hline \multirow[b]{2}{*}{ Age in years } & \multicolumn{4}{|c|}{ Body mass index } \\
\hline & $\begin{array}{c}\text { Underweight } \\
\text { n=47 } \\
\text { n }(\%)\end{array}$ & $\begin{array}{c}\text { Normal } \\
n=179 \\
n(\%)\end{array}$ & $\begin{array}{c}\text { Overweight } \\
\mathbf{n}=\mathbf{3 7} \\
\mathbf{n}(\%)\end{array}$ & $\begin{array}{l}\text { Obese } \\
\mathrm{n}=51 \\
\mathrm{n}(\%)\end{array}$ \\
\hline $16(\mathrm{n}=91)$ & $12(13.2)$ & $52(57.1)$ & $9(9.9)$ & $18(19.8)$ \\
\hline $17(\mathrm{n}=119)$ & $17(14.3)$ & $72(60.5)$ & 15 (12.6) & 15 (12.6) \\
\hline $18(\mathrm{n}=93)$ & $15(16.1)$ & $49(52.7)$ & $12(12.9)$ & 17 (18.3) \\
\hline $19(n=11)$ & $3(27.3)$ & $6(54.5)$ & $1(9.1)$ & $1(9.1)$ \\
\hline
\end{tabular}

n- Number of students.

Table 2: Students Response to obesity related questionnaire.

\begin{tabular}{|c|c|c|}
\hline \multirow{2}{*}{ Knowledge statements } & \multicolumn{2}{|c|}{ Correct answer } \\
\hline & Number & $\%$ \\
\hline 1. A person with a (beer-belly) shaped stomach has an increased risk of getting diabetes. (True) & 237 & 75.5 \\
\hline 2. Obesity increases the risk of getting bowel cancer. (True) & 135 & 43.0 \\
\hline 3. An obese person who gets diabetes needs to lose $40 \%$ of their bodyweight for clear health benefits. (False) & 137 & 43.6 \\
\hline 4. Obese people can expect to live as long as non-obese people. (False) & 106 & 33.8 \\
\hline 5. Obesity increases the risk of getting breast cancer after the menopause. (True) & 95 & 30.3 \\
\hline 6. There is no major health benefit if an obese person who gets diabetes loses weight. (False) & 64 & 20.4 \\
\hline 7. Obesity does not increase the risk of developing high blood pressure. (False) & 71 & 22.6 \\
\hline 8. It is better for a person's health to have fat around the hips and thighs than around the stomach. (True) & 127 & 40.4 \\
\hline 9. Obesity increases the risk of getting a food allergy. (False) & 137 & 43.6 \\
\hline
\end{tabular}

Table 3: Attitude of male high school students towards obese persons.

\begin{tabular}{|c|c|c|c|c|c|c|}
\hline & \multicolumn{6}{|c|}{ Attitude toward obese person } \\
\hline & $\begin{array}{c}+3 \\
\mathbf{N}(\%)\end{array}$ & $\begin{array}{c}+2 \\
N(\%)\end{array}$ & $\begin{array}{c}+1 \\
N(\%)\end{array}$ & $\begin{array}{c}-1 \\
N(\%)\end{array}$ & $\begin{array}{c}-2 \\
\mathbf{N}(\%)\end{array}$ & $\begin{array}{c}-3 \\
\mathbf{N}(\%)\end{array}$ \\
\hline Obese people are as happy as non obese people. & $47(15.0)$ & $70(22.3)$ & $33(10.5)$ & $40(12.7)$ & $80(25.5)$ & $44(14.0)$ \\
\hline Most obese people feel that they are not as good as other people. & $66(21.0)$ & $104(33.1)$ & $44(14.0)$ & $35(11.1)$ & $40(12.7)$ & $25(8.0)$ \\
\hline Most obese people are more self-conscious than other people. & $76(24.2)$ & $94(29.9)$ & $61(19.4)$ & $29(9.2)$ & $37(11.8)$ & $17(5.4)$ \\
\hline Obese worker cannot be as successful as other worker & $75(23.9$ & $80(25.5)$ & $40(12.7)$ & $20(6.4)$ & $45(14.3)$ & $54(17.2)$ \\
\hline Severely obese people are usually untidy & $76(24.2)$ & $86(27.4)$ & $44(14.0)$ & $32(10.2)$ & $37(11.8)$ & $39(12.4)$ \\
\hline Obese people tend to have family problems & $16(5.1)$ & $41(13.1)$ & $21(6.7)$ & $58(18.5)$ & $90(28.7)$ & $88(28.0)$ \\
\hline Obese people are usually sociable & $22(7.0)$ & $39(12.4)$ & $22(7.0)$ & $40(12.7)$ & $78(24.8)$ & $113(36.0)$ \\
\hline Most obese people are not dissatisfied with themselves & $100(31.8)$ & $96(30.6)$ & $33(10.5)$ & $16(5.1)$ & $38(12.1)$ & $31(9.9)$ \\
\hline Obese people are just as self-confident as other people & $94(29.9)$ & $73(23.2)$ & $34(10.8)$ & $36(11.5)$ & $52(16.6)$ & $25(8.0)$ \\
\hline Most people feel uncomfortable when they associate with obese people & $20(6.4)$ & $51(16.2)$ & $40(12.7)$ & $43(13.7)$ & $93(29.6)$ & $67(21.3)$ \\
\hline Obese people are often less aggressive than non obese people & $65(20.7)$ & $68(21.7)$ & $35(11.1)$ & $48(15.3)$ & $55(17.5)$ & $43(13.7)$ \\
\hline Most obese people have different personalities than non obese people & $61(19.4)$ & $110(35.0)$ & $40(12.7)$ & $39(12.4)$ & $39(12.4)$ & $25(8.0)$ \\
\hline Very few obese people are ashamed of their weight & $80(25.5)$ & $110(35.0)$ & $56(17.8)$ & $26(8.3)$ & $24(7.6)$ & $18(5.7)$ \\
\hline Obese people are more emotional than non obese people & $82(26.1)$ & $83(26.4)$ & $35(11.1)$ & $54(17.2)$ & $41(13.1)$ & $19(6.1)$ \\
\hline Obese people are just as healthy as non obese people & $25(8.0)$ & $23(7.3)$ & $11(3.5)$ & $51(16.2)$ & $104(33.1)$ & $100(31.8)$ \\
\hline
\end{tabular}

\footnotetext{
$>\quad-3$ strongly disagree -2 moderately disagree -1 slightly disagree
}

$>\quad+1$ slightly agree +2 moderately agree +3 strongly agree 
Table 4: Association between student's age and BMI with their knowledge of obesity and attitude towards obese person.

\begin{tabular}{|c|c|c|c|c|c|c|c|c|c|c|}
\hline & & \multicolumn{4}{|c|}{ Student's age (years) } & \multicolumn{4}{|c|}{ Body mass index } & \multirow[b]{2}{*}{$\begin{array}{c}\mathbf{X}^{2} \\
\text { (p-value) }\end{array}$} \\
\hline & & $16(n=91)$ & $17(n=119)$ & $18(n=93)$ & $19(n=11)$ & $\begin{array}{c}\text { Underweig } \\
\text { ht }(n=47)\end{array}$ & $\begin{array}{l}\text { Normal } \\
(n=179)\end{array}$ & $\begin{array}{c}\text { Over } \\
\text { weight } \\
(\mathbf{n}=37)\end{array}$ & $\begin{array}{l}\text { Obesity } \\
(n=51)\end{array}$ & \\
\hline Obesity & Insufficient $\mathrm{n}=241(\%)$ & $71(78.0)$ & $91(76.5)$ & $71(76.3)$ & $8(72.7)$ & $38(80.9)$ & $140(78.2)$ & $26(70.3)$ & $37(72.5)$ & 0.20 \\
\hline knowledge & Sufficient $\mathrm{n}=73(\%)$ & $20(22.0)$ & $28(23.5)$ & $22(23.7)$ & $3(27.3)$ & $9(19.1)$ & $39(21.8)$ & $11(29.7)$ & $14(27.5)$ & $(0.978)$ \\
\hline Attitude towards & Negative $\mathrm{n}=147(\%)$ & $39(42.9)$ & $61(51.3)$ & $41(44.1)$ & $6(54.5)$ & $17(36.2)$ & $90(50.3)$ & $14(37.8)$ & $26(51.0)$ & 2.06 \\
\hline obese person & Positive $\mathrm{n}=167(\%)$ & $52(57.1)$ & $58(48.7)$ & $52(55.9)$ & $5(45.5)$ & $30(63.8)$ & $89(49.7)$ & $23(62.2)$ & $25(49.0)$ & $(0.560)$ \\
\hline
\end{tabular}

n- Number of students

Table 5: Association between students`obesity knowledge and their attitude towards obese persons.

\begin{tabular}{|c|c|c|c|}
\hline \multirow[b]{2}{*}{ Attitude towards obese persons } & \multicolumn{2}{|c|}{ Obesity knowledge } & \multirow[b]{2}{*}{$X^{2}(p-v a l u e)$} \\
\hline & $\begin{array}{c}\text { Insufficient } \\
\mathrm{n}=69 \\
\mathrm{n}(\%)\end{array}$ & $\begin{array}{c}\text { Sufficient } \\
\mathrm{n}=245 \\
\mathrm{n}(\%)\end{array}$ & \\
\hline Negative $(n=147)$ & $35(23.8)$ & $112(76.2)$ & 0.54 \\
\hline Positive $(n=167)$ & $34(20.4)$ & $133(79.6)$ & $(0.461)$ \\
\hline
\end{tabular}

n- Number of students

\section{DISCUSSION}

This study reveals relatively high widespread presence of overweight and obesity among the male adolescent population in Al-Madinah, KSA. The prevalence of overweight $(11.8 \%)$ and obesity $(16.2 \%)$ observed in this study are comparable with overweight (13.4\%) and obesity (13.5\%) observed among adolescents in Jeddah (Abalkhail et al., 2002), overweight (13.8\%) and obesity $(20.5 \%)$ reported among adolescent males in Riyadh (Al-Rukban, 2003). The extensiveness of overweight and obesity observed in the current study are within the range compared to other Arab countries (Musaiger et al., 2012).

The relatively high widespread presence of obesity in male adolescents in Madinah, KSA indicates that the community has undergone intense social and behavioral modifications over last few decades (Al-Rukban, 2003).

Obesity is fast turning out to be a major cause of concern for the Kingdom with seven out of 10 Saudis suffering from obesity, A recent study revealed that a whopping SR500 million per year was spent by people suffering from obesity in the Kingdom on treatment (Musaiger et al., 2012).

The distinct differences in the overweight and obesity rates observed from various studies conducted in different parts of KSA may be partly associated with the difference in socioeconomic standing of the study population, because social status is a key factor to nutritional habit which in turn is a risk factor of overweight and obesity (Fouzia, 2014).

Another study indicates high rates of obesity across all segments of the population in KSA and the reason found was most Saudis are physically inactive and consume low levels of fruits and vegetables. Furthermore, strong associations were found between obesity and diabetes, hypercholesterolemia, and hypertension (Ziad et al., 2014).

In the present study, knowledge of obesity-related risk factors (ORK) was insufficient and it was not significantly associated with BMI and age of the students. A UK prospective study measured ORK in 66 patients who have attended National Health Service (NHS) weight management clinic for 18 months. Above study was conducted to find whether ORK was associated with greater weight loss (Lee and Ahn, 2007). ORK-10 scores amongst the 66 participants were relatively low, which was surprising considering they have been attending weight management clinic for 18 months. In addition, there was no significant $(p=0.31)$ association between weight loss and ORK-10 scores.

In the current study almost half of the male high schools students in Al-Madinah had positive attitude towards obese persons and no significant difference was observed between attitude towards obese persons with BMI and age of the students. A study carried out by Gipson et al. 2005 in 191 students attending Virginia State University measured attitudes towards obese persons by utilizing ATOP scale questionnaire (Gipson et al., 2005).

They revealed no significant difference in attitudes between gender and BMI categories. Similar findings were apparent from a study conducted in Korean fifth grade students (Lee and Ahn, 2007).

From literatures, positive attitudes towards obese persons were apparent amongst 10-12year olds; this suggests that negative attitudes may begin in older aged participants.Vartanian, 2010 revealed mixed findings regarding age and BMI as predictors of attitudes (Vartanian, 2010).

Although this study revealed no association between knowledge of obesity related risk factors and attitude towards obese person with BMI and age of the student, the results analysis should be made by considering some limitations. Only male students were enrolled in the study and these students' knowledge level does not depict other student's knowledge either nationally or internationally, the differences found might be due to socioeconomic status of the study participants. 


\section{CONCLUSION}

The study revealed relatively high prevalence of overweight and obesity among the male adolescent population in Al-Madinah, KSA. Overall, the knowledge of the students regarding obesity risk factors is insufficient whereas their attitude towards obese persons is considered satisfactory. Students' knowledge regarding obesity risk factors and attitude towards obese persons were independent of their age/BMI. In order to decrease the prevalence of obesity among school students, addressing the problems \& late consequences of obesity in school curriculum with emphasis on its risk factors should be considered.

\section{Financial support and sponsorship: Nil.}

Conflict of Interests: There are no conflicts of interest.

\section{REFERENCES}

Abalkhail BA, Shawky S, Soliman NK. Validity of selfreported weight and height among Saudi school children and adolescents.Saudi Med J, 2002; 23:447-53.

Al-Hazzaa HM, Abahussain NA, Al-Sobayel HI, Qahwaji DM, Alsulaiman NA, Musaiger AO. Prevalence of overweight, obesity, and abdominal obesity among urban Saudi adolescents: Gender and regional variations. J Health Popul Nutr, 2014; 32(4):634-45

Ali AS, Areej AF, Ibrahim AA. Obesity among Saudi children. Saudi J Obesity, 2013:1(1);3-9.

Allison DB, Basile VC, Yuker HE. The measurement of attitudes toward and beliefs about obese persons. Int J Eat Disord, 1991;10:599-607.

Al-Rukban MO. Obesity among Saudi male adolescents in Riyadh, Saudi Arabia.Saudi Med J, 2003; 24(1):27-33.

Artur M, Paweł M, Krista R, Sergey N, Piotr S, Monika BB et al. Childhood Obesity: Knowledge, Attitudes, and Practices of European Pediatric Care Providers. Pediatrics ,2013:132(1); 100-8

Bonauto DK, Lu D, Fan ZJ. Obesity prevalence by occupation in Washington State, Behavioral Risk Factor Surveillance System.Prev Chronic Dis 2014;11:1-9.

Centres for Disease Control and Prevention, Atlanta.Childhood overweight and obesity. Available at: http://www.cdc.gov/needphp/dupa/ obesity/defining.html.[Accessed 2013 June 25].

Fouzia Khan. $70 \%$ of Saudis are obese, says study. Published: Monday $17^{\text {th }}$ February 2014. Available at: http://www.arabnews.com/ news/527031. [Accessed 2013 July 5].

Gipson GW, Reese S, Vieweg VR., Anum EA, Pandurangi AK, Olbrisch, ME, et al. Body image and attitude toward obesity in an historically black university. J Natl Med Assoc, 2005; 97(2): 225-36.

Hoffmann SW, Tug S, Simon P. Obesity prevalence and unfavourable health risk behaviours among German kindergarten teachers: cross-sectional results of the kindergarten teacher health study. BMC Public Health, 2013; 13: 927.
Karageorgi S, Alsmadi O, Behbehani K. A Review of AdultObesity prevalence, trends, risk factors, and epidemiologic methods in Kuwait.J Obes, 2013;2013:1-14.

Kline P. 2000. The Handbook of Psychological Testing 2nd edn. Routledge: London.

Krebs NF, Himes JH, Jacobson D, Nicklas TA, Guilday P, Styne D. Assessment of child and adolescent overweight and obesity. Pediatrics, 2007; 120: S193-S228.

Lee S, Ahn H. Relation of obesity-related attitudes, knowledge, and eating behaviors with body weight and body shape satisfaction in 5th grade Korean children. Nutr Res Pract, 2007; 1(2): 126-30.

Mazur A, Matusik P, Revert K, Nyankovskyy S, Socha P, Binkowska-Bury M, et al. Childhood obesity: Knowledge, attitudes, and practices of European paediatric care providers. Paediatrics, 2013; 132(1):100-8.

Musaiger AO, Al-Mannai M, Tayyem R, Al-Lalla O, Ali EYH, Kalam F, et al. Prevalence of Overweight and Obesity among Adolescents in Seven Arab Countries: A cross-cultural Study. J Obes, 2012:5: Article ID-981390.

National Center for Health Statistics. 2012. Health, United States, 2011: With Special Features on Socioeconomic Status and Health .Hyattsville, MD; U.S. Department of Health and Human Services.

Non-communicable diseases: Fact sheet WHO. (Updated January 2015). Available at: (http://www.who.int/mediacentre/factsheets/ fs355/en/ [Accessed 2015 January 12]

Obesity and overweight. Fact sheet WHO. (Updated January 2015). Available at: http://www.who.int/mediacentre/factsheets/ fs311/en/. [Accessed 2015 January 10]

Ogden CL, Carroll MD, Kit BK, Flegal KM. Prevalence of childhood and adult obesity in the United States, 2011-2012. Journal of the American Medical Association, 2014;311(8):806-814

Swift JA, Glazebrook C, Macdonald I. Validation of a brief, reliable scale to measure knowledge about the health risks associated with obesity. Int J Obes, 2006; 30: 661-8.

Vartanian LR. Disgust and perceived control in attitudes toward obese people.Int J Obes, 2010; 34(8):1302-7.

Ziad AM, Charbel EB, Marwa T, Margaret R, Farah D, Sara T, et al. Obesity and Associated Factors: Kingdom of Saudi Arabia, 2013. Prev Chronic Dis, 2014; 11: 140236.

\section{How to cite this article:}

Al-Qahtani AM, Sundogji H. Attitudes and knowledge of obesity risks among Male high school students in Al-Madinah, Saudi Arabia. J App Pharm Sci, 2016; 6 (10): 154-158. 